riado metalúrgico näo foi capaz de romper com essa logica do poder politico do capital". Além disso. acrescenta, "a ausência de wma direção politica consciente, dotada de independência térica $e$ ideologica, impossibiliton a visualização plena da confextualizaçâo social e politica vigente, levando o mozimento à derrota" (p. 169; grifos do original).

Na segunda parte de $A$ Rebeldia do Trabalho, o autor faz uma caracterização do proletariado metalúrgico do $\mathrm{ABC}$ paulista, avançando também "na tematizaçüo dos elementos causais que possibilitaram o ressurgimento grevista a partir do pólo metulúrgico vinculado ao ramo automobilisti$c^{\prime \prime}(p, 8)$. A irrupção da crise econômica, cujos sintomas transpareceram já no final de 1973 (com o esgotamento do chamado "milagre brasileiro"), "ao aflorar a necessidade de reordenar e recompor os diversos interesses das frações dominantes aue se articulavam em torno do tripé, capital monopolista externo, capital monopolista privado nacional e setor produtivo estatal", atingiu diretamente a forma pela qual o aparato estatal se estruturava. Competia ao aparato estatal através de um rearranjo do bloco no poder "forjar alternativas que näo trouxessem ônus em demasia para as fraçóes monopolistas dominantes". Nesse sentido, a crise assumia uma dimensão política explícita (p.112). Aproveitando-se das metamorfoses do poder político bonapartista $e$ das dissençóes que afloravam no bloco no poder, deu-se "o ressurgimento do movimento operário, desmistificando o projeto 'aberturista', desnudando seu carater de transição 'pelo alto'; por' dentro do poder ditatorial. Por isto, constitui-se em obstáculo que forçou o prolongamento da estratégia polticica de auto-reforma do poder politico e da dominação autocrática" (p. 126).

Nas conclusōes, Ricardo Antunes desenvolve as categorias fundamentais presentes no fenomeno social da greve, apontando os nexos existentes entre os processos efetivos de greves e suas manifestaçóes ao nível da consciência operária nas greves de 1978 e 79 e, também, mostra as limitaçöes presentes na greve de 1980. Encerra com uma reflexão teórica acerca das conexões existentes entre os processos efetivos de greve e o desenvolvimento da consciência do ser social que trabalha.

Nas palavras de Florestan Fernandes, autor da "Apresentaçăo", o livro de Ricardo Antunes retoma, em conjunto, "uma vasta documentação sobre as Greves do $A B C$ e lança um desafio. De um Lado, os operários, ao negar a empresa $e$ o capital, negam o govermo ditatorial e sua politica econômica (..). De outro lado, estä o desafio. Os operúrios chegaram atê at (...). A fronteira agora é mais ampla (...), é preciso derrotar simultaneamente o arro cho dos salátios e o solapamento dos padrôes de soltdariedade de classe. Esses fatos são cruciais. Eles colocam o Brasil no limiar de uma nova era." $\square$

\section{MANUAL DE PREPARAÇÄO DE ESTUDOS DE VIABILIDADE INDUSTRIAL}

\author{
UNIDO - ORGANIZAÇÃO PARA O \\ DESENVOLVIMENTO INDUSTRIAL DAS NAÇÖES \\ UNIDAS \\ Traduzido do inglès, Manual for the \\ Preparation of Industrial Feasibility Studies (1987), \\ por Antonio Norival Brito Rabelo. \\ São Paulo, Editora Atlas, 1987.

\section{Por Kurt Ernst Weil} \\ Professor no Departamento de Administraçăo de \\ Produçăa e Operaçōes Industriais da \\ EAESPIFGV.
}

Como se nota, trata-se de um livro escrito por tum grupo, sabendo-se pelos agradecimentos e pela bibliografia que houve o uso de diversas publicações prévias da ONU e da UNIDO. Apeșar da predominância de autores árabes $\mathrm{e}$ da Índia, o livro mantém uma excelente unidade e é realmente de uso geral - independente do país onde é aplicado, mesmo quando não é do Terceiro Mundo. A existência da colaboração de Friederich Giersig deu um toque de literatura alemã à bibliografia, que geralmente é em inglês e francềs, o que é ótimo,

Gostei muito do livro, acho-o ótimo como literatura e livro-texto na área, mas precisa ser complementado por no mínimo cinco tipos de publicações sobre os seguintes tópicos:

$1 \%$ Ecologia, Meio Ambiente e Poluição Ambiental. As referências das páginas 108 , impactos ambientais, e página 119 , pocira e fumaça, são insuficientes;

$2^{\circ}$ Financiamento de projetos (pág. 176) referências insuficientíssimas (págs. 112 e 199);

$3^{2}$ Engenharia Econômica: retorno (pág. 211 a 227);

4. Teoria e prática internacional de patentes, royalties, marcas etc. só são mencionados de leve;

$5^{2}$ Custo-benefício, análise e prática.

A rica bibliografia dă livros em abundância para todas essas áreas, mas nada em português. No entanto, existem livros para todas as necessidades em português.

Talvez não ter feito uma bibliografia brasileira seja o único senão do tradutor e adaptador Antonio Norival Brito Rabelo. Não encontrei erros no texto; a tradução é muito boa, não senti falta do original. Parabéns.

O livro pretende ser um guia - e alcança este objetivo. Năo concorre com os livros editados, nacionais ou traduzidos, da $\mathrm{APEC}$, da década de 60 e 70 , tal como o de Solomon, M., 
Análise de projetos; nem com os livros sobre projetos de engenharia, tal como o de Asimow, Morris, Introduça ao Projeto de Engenharia, Mestre Jou. Os dois livros citados são predominantemente matemáticos no tratamento e me trouxeram lembranças da época de CPM, PERT e da primeira alegria de usar o modelo de Domar. O volume da UNIDO é pós-moda custobeneficio - que nem consta do índice remissivo, mas $e$ indubitavelmente necessário para a escolha de projetos por meio de um ranking social em paises do Terceiro Mundo. (Tratamento de esgotos ou metrô? Água tratada em rede de distribuição ou nova hidro-elétrica?)

Custo-benefício social é de interesse inesgotável e a quantificação de, por exemplo, lazer na saúde é fascinante; a imensa metafísica de palavras para a decisão é a alegria das comissōes ad hoc e permanentes de investimentos em economias dirigidas.

O livro recomendado para complementar esta parte é o de Michan, Introduçüo à Analise Custo-Beneficio, Ed. Zahar.

Finalmente, há um excelente livro nacional, de Cyro Eyer do Valle - Implantacyo de Indistrias, Livros Técnicos \& Cientificos Editora S.A. 1975 - que, em 337 páginas, esgota mais alguns aspectos do assunto da viabilidade, do seguro a ser feito etc.

Como estou citando muitos livros, é possivel deduzir que na realidade o livro da UNIDO é um resumo perfeito - mas precisa ser complementado por uma biblioteca para ser usado por modernos empresários. Precisa desde planejamento estratégico, previsão, até detalhes de análise financeira.

O que faz a UNIDO para tornar o livro importante e excelente? Ela apresenta quadros e resumos, check-lists (para nada ser esquecido) e alguma matemática, problemas de contabilidade, de custos, de retomo, ponto de equilibrio, elasticidade etc.

$\mathrm{O}$ que me tornou mais feliz, entretanto, foi encontrar a fórmula de investimentos:

$$
C_{1}=\frac{C_{2}\left(Q_{1}\right)^{x}}{\left(Q_{2}\right)}
$$

onde: $C_{1}$ é o custo devido à capacidade $Q_{1}$

$\mathrm{C}_{2}$ é o custo devido à capacidade $\mathrm{Q}_{2}$

$\mathrm{x}=$ fator custo-capacidade (na média 0,6 )

Esta fórmula é originária da revista Chemical Engineering, que costuma apresentâ-la da maneira seguinte:

"Cada vez que dobra a capacidade de instalaçóes o custo é multiplicado por 1,5 a $1,7^{\prime \prime}$.

Na prătica, essa fórmula se baseia na relação área (envolucro) $=$ volume, pois a área cresce no quadrado e o volume no cubo. O autor desta resenha ensina essa relaçäo por meio de uma comparação com o preço de venda de panelas de pressăo de 4 e de 7,5 litros, respectivamente, passando para o dobro do volume.

Então, volume $=4: 8$ Raio de base do cilindro $1,585: 2,0$

Relação da área (superficie externa):

$$
1,582^{2}: 2,0^{2}=2,51: 4=1,6
$$

Portanto, 1,6 é o fator pelo qual a superficie e o preço crescem, quando dobra o volume.

Essa fórmula ê fundamental no investimento e em compras de ativo fixo. O custo-beneficio deve ser calculado entre a compra de, por exemplo, duas caldeiras de $10.000 \mathrm{~kg} /$ vapor a $100 \mathrm{lbs} /$ hora ou uma de $20.000 \mathrm{~kg}$.

É a subida do preço na relação $1: 1,6$ - a economia de $20 \%$ contrapôe-se à segurança de duas unidades paralelas, que permitem manutenção em separado.

O livro apresenta os seguintes capítulos:

$1^{2}$ parte - Aspectos e categorias dos estudos pré-investimento

$2^{\text {s}}$ parte $\quad-$ Oestudo de viabilidade

Capítulos:

2.I - Sumário executivo

2.II - Histórico do projeto

2.III - Mercado e capacidade da fábrica

2.IV - Materiais e insumos

2.V-Materiais e insumos

2.VI - Engenharia do projeto

2.VII - Organizaçẫo da fábrica e despesas indiretas

2.VII -Recursos Humanos

2.IX - Programa de implantação

2.X-Avaliaçào financeira e econômica

Anexos:

I - Perfil de estudos gerais e de oportunidades

Il -.-Perfil de estudos de pré-viabilidade

III - Prática de estudos

IV - Tipos de decisôes

$V$-Situação de uma empresa já existente

VI - Previsão de demanda

VII - Estudo de mercado

VIII - Demonstraçōes financeiras

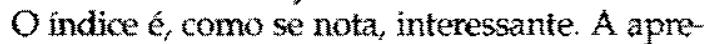
sentação é sem conotação ideológica, considerando que a origem são as Naçoóes Unidas. A clareza, inclusive da tradução, permite o entendimento mesmo por pessoas de simples conhecimentos de engenharia, de economia ou de administração. (Sem querer ofender outras profissões, quero dizer que a apresentação está ao alcance de quem tiver alguma prática na técnica de administração ou avaliação de indústrias.)

O preço de $\mathrm{NCz} \$ 9,70$ é relativamente caro. mas justificável. Há boa apresentação gráfica e espero que o livro resista, mesmo se vier a ser tão manuseado quanto merece. 